\title{
Devices for Dry Powder Drug Delivery to the Lung
}

\author{
Kai Berkenfeld, ${ }^{1,2}$ Alf Lamprecht, ${ }^{2}$ and Jason T. McConville ${ }^{1,2,3}$
}

Received 7 March 2014; accepted 25 February 2015; published online 12 May 2015

\begin{abstract}
Dry powder inhalers (DPIs) are an important and increasingly investigated method of modern therapy for a growing number of respiratory diseases. DPIs are a promising option for certain patient populations, and may help to overcome several limitations that are associated with other types of inhalation delivery systems (e.g., accuracy and reproducibility of the dose delivered, compliance and adherence issues, or environmental aspects). Today, more than 20 different dry powder inhalers are on the market to deliver active pharmaceutical ingredients (APIs) for local and/or systemic therapy. Depending on the mechanism of deagglomeration, aerosolization, dose metering accuracy, and the interpatient variability, dry powder inhalers demonstrate varying performance levels. During development, manufacturers focus on improving aspects characteristic of their specific DPI devices, depending on the intended type of application and any particular requirements associated with it. With the wide variety of applications related to specific APIs, there exists a range of different devices with distinct features. In addition to the routinely used multi-use DPIs, several single-use disposable devices are under development or already approved. The recent introduction of disposable devices will expand the range of possible applications for use by including agents such as vaccines, analgesics, or even rescue medications. This review article discusses the performance and advantages of recently approved dry powder inhalers as well as disposable single-use inhalers that are currently under development.
\end{abstract}

KEY WORDS: disposable; dry powder inhaler; particle deagglomeration; vaccination.

\section{INTRODUCTION}

Drug delivery to the lungs first became widely accessible in modern clinical practice with the development of commercially available pressurized metered dose inhalers (pMDIs) for the treatment of asthma by Riker Laboratories in 1956 (1). Although this was a milestone for the therapy of pulmonary diseases, concerns arose in 1974 when the contribution of chlorofluorocarbon (CFC) propellants to the depletion of the ozone layer was hypothesized (2). As requested by the Montreal Protocol in 1987, CFCs eventually were substituted in 1995 by more "environmental friendly" hydrofluoroalkane (HFA) gases, which were shown not to disturb the oxygen/ ozone equilibrium in the upper stratosphere (3-6). It has since been realized that HFA gases are up to 2000-fold more potent than carbon dioxide as greenhouse gases, even so they are estimated to contribute less than $0.1 \%$ to global greenhouse gas emission $(7,8)$. pMDIs also suffer from potential

\footnotetext{
$\overline{{ }^{1} \text { College of Pharmacy, University of New Mexico, Albuquerque, New }}$ Mexico, USA.

${ }^{2}$ Laboratory of Pharmaceutical Technology and Biopharmaceutics, Friedrich-Wilhelms-Universität, Bonn, Germany.

${ }^{3}$ To whom correspondence should be addressed. (e-mail: jmcconville@unm.edu)
}

difficulties caused by the propellant used $(9,10)$. Depending on if the drug is being formulated as solution or suspension, issues, e.g., low solubility (11) and chemical instability of the active pharmaceutical ingredient (API) (12) or crystal growth phenomena (13) and instability of the suspension (14), respectively, arise. This leads to potentially inaccurate dose metering and a limited drug loading capacity (11). Additionally, the low efficiency of drug targeting to the small airways and reformulation difficulties have been discussed as potential drawbacks for pMDI formulations. Clinically, patient compliance may be compromised with bronchoconstriction issues (i.e., Freon effect) (15), and/or the need to actuate the pMDI delivery device simultaneously with patient inspiration, and a complex inhalation maneuver, especially in certain patient subpopulations $(16,17)$. One approach in an attempt to overcome these limitations was the development of dry powder inhalers (DPIs). In 1967, Fisons (Ipswich, UK) launched the Spinhaler ${ }^{\circledR}$ device (7). Since then, remarkable advances in DPI technology have been made with many devices entering the market, although pMDIs remain the predominant technology sold and used due to their wide acceptance and convenience (18). More than 20 different DPI devices from various manufacturers are currently available, and several more are under development or in clinical trials. Aside from the classical treatment of the airway diseases such as asthma and chronic obstructive pulmonary disease (COPD) (19), several inhalable products for systemic 
drug delivery are already approved and marketed (20), or are under development $(21,22)$. Additionally, there has recently been increasing interest in the development of single-use disposable dry powder inhalers (23). This review is intended to give an update on recently approved and new DPI devices, as well as an overview on the latest advances in development and approval of single-use dry powder inhalation devices.

\section{GENERAL REQUIREMENTS FOR DRY POWDER INHALATION DEVICES}

Inhalation devices are designed to reproducibly deliver a predefined dose of a drug to the small airways and alveolar region of the lung. It is well reported that particles with a mass median aerodynamic diameter (MMAD) of 1-5 $\mu \mathrm{m}$ are effectively deposited at aforementioned sites (24). The MMAD of a particle depends on its geometrical diameter, density, and morphology with these properties generally being manipulated during the manufacturing process (25). Due to interparticulate forces, i.e., mechanical interlocking, capillary, electrostatic, and van der Waals forces (26), micronized powders are very adhesive/cohesive, spontaneously forming agglomerates. The extent of the partial and consequently of the combined forces is dependent on powder properties such as particle size, morphology, shape, and material (27), as well as on environmental factors, e.g., relative humidity (28). Since the extent of agglomeration negatively affects the fraction of the inhaled powder, which is within the respirable range (29), these agglomerates must be effectively deagglomerated prior to or during the processes of aerosolization and inhalation (30). DPIs that utilize a patient's inspiratory airflow to provide the required energy to overcome the aforementioned interparticulate forces are known as "passive" devices, whereas those that utilize other sources of energy are referred to as "active" devices. One advantage of utilizing a patient's inspiratory airflow as the main source of energy is that such devices are breath actuated; this inherently avoids the need to synchronize the actuation and inspiration maneuver by the patient. The downside of this approach is that devices currently available show a device-specific airflow resistance, and this often demands a relatively high inspiratory effort (31) which might be a hurdle for patient populations suffering from obstructive airway diseases such as asthma or COPD, the elderly, or very young (32). The extent of lung deposition is also dependent on the individual patient's inspiratory flow rate causing a potential difference in the dose effectively delivered due to this variability (33). Another critical factor affecting the reproducibility of doses delivered by multidose inhalers is dose metering. While single-dose and multi-unit dose devices use premetered powders packed into blisters or capsules, powder bed bulk multidose inhalers use powder reservoirs so that the dose to be delivered has to be separated from the bulk material prior to actuation (34). For both types of devices, suitable powder flow properties are essential, either for accurate dosing or emptying of the single-dose container entirely. Since flow properties of micronized powders are often poor, most formulations consist of physical blends of drug particles with larger $(30-90 \mu \mathrm{m})$ carrier particles such as lactose, to aid deagglomeration and powder flow (35). In light of the aforementioned considerations, the ideal DPI would reproducibly deliver an accurate dose, regardless of a patient's condition. Clinically, it may also be advantageous if the device is breath actuated, easy, and safe to use, offers some type of control feedback mechanism (related to efficacy), and has an accurate dose counter. The dose counting mechanism is a standardized requirement that serves to help patients to track whether doses have been administered appropriately, and when to replace the device at a suitable time $(16,36)$.

\section{COMMERCIALLY AVAILABLE DPI DEVICES}

As discussed in the previous section, safety and efficacy of local as well as systemic dry powder inhalation therapies are dependent in part on the characteristics of the inhalation device and formulation properties that are used. Over the past 50 years, numerous DPI devices have been developed and marketed, and there has been a steady evolution in improvement of inhaler characteristics. The first generation DPI devices, such as the Spinhaler (Fisons, Ipswich, UK) and Rotahaler® (Glaxo, London, UK), had poor aerosolization performances with relatively low amounts of drug in the range of 1-5 $\mu \mathrm{m}$, defined as the fine particle fraction (FPF), of approximately $10 \%(37,38)$. Generation two DPI devices, e.g., the Handihaler ${ }^{\circledR}$ (Boehringer-Ingelheim, Ingelheim am Rhein, Germany), can achieve FPFs of more than 20\% (39). State-of-the-art devices like the Genuair ${ }^{\circledR}$ (Almirall Sofotec GmbH, Bad Homburg v.d. Höhe, Germany) perform even better, creating FPFs of more than 30\% (40). Similar considerations can be applied with respect to airflow resistance or total emitted dose (TED). Table I gives an overview of several dry powder inhalation devices that are currently marketed, and, since they have already been extensively discussed elsewhere in the literature, they will not be discussed at length in this review.

Over the last five years, several new dry powder inhalation devices have gained approval (Table II). Approved in Spring 2013, the TOBI® Podhaler ${ }^{\circledR}$ (Novartis, Basel, Switzerland) offers a new therapeutic option for patients suffering from chronic Pseudomonas infections associated with cystic fibrosis. TOBI Tobramycin Inhalation Solution (TIS TM) (Novartis, Basel, Switzerland) was already available in the USA as of 1997 for inhalation via the LC® Plus jet-nebulizer (PARI Respiratory Equipment Inc., Midlothian, VA, USA). Drawbacks of this regimen were relatively long inhalation times, and the need of cleaning the nebulizer after every use, which may have led to the risk of lung infection from devices that were not cleaned properly. Furthermore, nebulizers are somewhat bulky, and this particular type requires a compressed air supply/generator in order to be operated. Additionally, TIS has to be refrigerated when stored $(46,47)$, or the product may suffer degradation prior to use. Considering the aforementioned limitations, more convenience for those patients qualifying for using the TOBI Podhaler, a certain minimum inspiratory performance and compliance are required, and increased adherence can be expected $(47,48)$. Much effort has been made to find alternative routes of administering insulin in a way that would avoid using needles, which is expected to increase the therapeutic comfort of the patient (49), as well as the safety of the therapy, since the risk of hypoglycemia events would be reduced (50). Starting another attempt to clinically accepted pulmonary diabetes therapy, Afrezza ${ }^{\circledR}$ (MannKind Corp., Valencia, CA, USA), using 
Table I. Overview on Selected Inhalers Currently Marketed

\begin{tabular}{|c|c|c|c|c|c|c|}
\hline DPI & Drug delivered & DPI type & $\begin{array}{l}\text { Formulation } \\
\text { storage }\end{array}$ & Reusable? & Company & Reference \\
\hline Spinhaler & $\mathrm{SC}$ & Single dose & Capsule & Yes & Aventis & $(15,16,41,43,44)$ \\
\hline Rotahaler/DPhaler® & SS, BDP & Single dose & Capsule & Yes & GSK/Cipla & $(15,41,43,44)$ \\
\hline $\begin{array}{l}\text { Cyclohaler®/ } \\
\text { Aerolizer® }\end{array}$ & SS, BDP, IBR, BUD, FOR & Single dose & Capsule & Yes & $\begin{array}{l}\text { Pharmachemie/ } \\
\text { Novartis }\end{array}$ & $(16,43,44)$ \\
\hline Handihaler & TT & Single dose & Capsule & Yes & $\begin{array}{l}\text { Boehringer- } \\
\text { Ingelheim }\end{array}$ & $(44)$ \\
\hline Turbuhaler & FOR, TS, BUD & Multidose & Reservoir & No & Astra Zeneca & $(15,16,41,43,44)$ \\
\hline Diskhaler® & SX, ZAN & Multi-unit dose & Blister pack & Yes & GSK & $(16,43)$ \\
\hline Diskus ${ }^{\circledR}$ & SS, SX, FLU & Multi-unit dose & Blister strip & No & GSK & $(41,44)$ \\
\hline Aerohaler ${ }^{\circledR}$ & IBR & Single dose & Capsule & Yes & $\begin{array}{l}\text { Boehringer- } \\
\text { Ingelheim }\end{array}$ & $(42,43)$ \\
\hline Easyhaler® & BUD, BDP, SS, FOR & Multidose & Reservoir & No & Orion & $(15,41,43)$ \\
\hline Pulvinal ${ }^{\circledR}$ & BDP, SS & Multidose & Reservoir & No & Chiesi & $(15,43)$ \\
\hline Novolizer & SS, BUD, FOR & Multidose & Cartridge & Yes & MEDA & $(15,16,42,43)$ \\
\hline Turbospin & $\mathrm{COL}$ & Single dose & Capsule & Yes & PH\&T & $(42)$ \\
\hline $\begin{array}{l}\text { MAGhaler®/ } \\
\text { Jethaler }{ }^{\circledR}\end{array}$ & BUD & Multidose & Ring tablet & No & Ratiopharm & $(15,41)$ \\
\hline Taifun ${ }^{\circledR}$ & SS & Multidose & Reservoir & No & LAB Pharma & (15) \\
\hline Clickhaler ${ }^{\circledR}$ & SS, BDP & Multidose & Reservoir & No & Recipharm & $(15,41-44)$ \\
\hline Flexhaler ${ }^{\circledR}$ & BUD & Multidose & Reservoir & No & AstraZeneca & $(45)$ \\
\hline Twisthaler ${ }^{\circledR}$ & $\mathrm{MF}$ & Multidose & Reservoir & No & Merck & $(43,44)$ \\
\hline
\end{tabular}

$B D P$ beclomethasone dipropionate, $B U D$ budesonide, $C O L$ colistimethate sodium, FLU fluticasone propionate/furoate, FOR formoterol hemifumarate, $I B R$ ipratropium bromide, $S C$ sodium cromoglycate, $S S$ salbutamol sulfate, $S X$ salmeterol xinafoate, $T S$ terbutaline sulfate, $T T$ tiotropium, $Z A N$ zanamivir

MannKind's proprietary TechnoSphere® technology delivered by the Dreamboat ${ }^{\mathrm{TM}}$ inhaler, was given FDA approval for the delivery of rapid acting recombinant insulin in 2014 (51). Most of the recently launched DPIs are approved for the administration of novel APIs or API combinations, especially for the treatment of asthma and COPD. Clinical evaluation and therapeutic benefit of those novel drugs are beyond the scope of this review, and will therefore not be discussed. An overview on selected performance characteristics of the inhalers discussed in the following sections is given in Table III.

\section{Genuair}

The Genuair (Almirall Sofotec GmbH, Bad Homburg v.d. Höhe Germany), marketed as Pressair $®$ in the USA, is a multidose disposable inhalation device that was approved in
2012 for the delivery of aclidinium bromide (52), an antimuscarinic drug for the treatment of COPD. The design resembles the Novolizer ${ }^{\circledR}$ (Novartis, Basel, Switzerland), the precursor in its development. It offers visual and audible feedback control mechanisms for priming, and for the correct inhalation maneuver. In order to prime the device, the patient is required to push and release a button on the rear of the device, triggering the release of a single dose from a nonremovable cartridge. A control window changes from red to green, indicating that the device is primed and ready for use. An audible click indicates correct inhalation and the control window changes back to red. Once the device is primed, a trigger threshold mechanism prevents accidental release of an additional dose. Particle deagglomeration is achieved by a cyclone separator (53). In vitro experiments using a five-stage multistage liquid impinger (MSLI) at a flow

Table II. Recent Approvals

\begin{tabular}{llllll}
\hline Product & \multicolumn{1}{c}{ Inhaler } & \multicolumn{1}{c}{ Company } & \multicolumn{1}{c}{ Approved } & \multicolumn{1}{c}{ Drug } & \multicolumn{1}{c}{ Indication } \\
\hline TOBI & Podhaler & Novartis & March 2013 & TOB & Cystic fibrosis (infection) \\
Breo ${ }^{\circledR}$ & ELLIPTA $®$ & GSK & May 2013 & FLU/VIL & Asthma \\
Anoro ${ }^{\circledR}$ & ELLIPTA $\AA$ & GSK & December 2013 & UME/VIL & COPD \\
Tudorza ${ }^{\circledR}$ & Pressair/ & Almirall & July 2012 & ABR & COPD \\
& Genuair & & & & \\
Adasuve & Staccato & Teva select brands & December 2012 & LOX & CNS disorder \\
Arcapta ${ }^{\circledR}$ & NEOhaler ${ }^{\circledR}$ & Novartis & July 2011 & IND & Asthma \\
Aridol ${ }^{\circledR}$ & dto & Pharmaxis & October 2010 & MAN & Bronchial challenge testing \\
Foster ${ }^{\circledR}$ & NEXThaler & Chiesi & July 2012 (Europe) & BDP / FOR & Asthma \\
Inavir ${ }^{\circledR}$ & TwinCaps & Daiichi Sankyo & September 2010 (Japan) & LAN & Viral infection (postexposition prophylaxis) \\
Afrezza ${ }^{\circledR}$ & Dreamboat & MannKind & June 2014 & INS & Types 1 and 2 diabetes mellitus
\end{tabular}

$A B R$ aclidinium bromide, $B D P$ beclomethasone dipropionate, $F L U$ fluticasone furoate, $F O R$ formoterol hemifumarate, IND indacaterol maleate, INS insulin, $L A N$ laninamivir, $L O X$ loxapine, $M A N$ mannitol, TOB tobramycin, UME umeclidinium bromide, VIL vilanterol 
Table III. Overview on Selected Performance Characteristics of Inhalers Reviewed

\begin{tabular}{llllll}
\hline \multicolumn{1}{c}{ DPI } & \multicolumn{1}{c}{ DPI type } & Formulation storage & FPF $[\%]$ & MMAD $[\mu \mathrm{m}]$ & Airflow resistance $\left[\mathrm{kPa}{ }^{0.5} \mathrm{~min} / \mathrm{L}\right]$ \\
\hline Genuair & Multidose & Cartridge & $40.3 \pm 5.6$ & n.r. & 0.031 \\
Breezhaler & Single dose & Capsule & $26.8 \pm 5.8$ & $3.2 \pm 0.22$ & 0.02 \\
Podhaler & Multi-unit dose & Capsule & n.r. & n.r. & 0.025 \\
NEXThaler & Multidose & Reservoir & $54.5-67.6$ & n.r. & 0.036 \\
Twincer & Different makes & & $23-60$ & n.r. & n.r. \\
Conix & Different makes & & 85 & n.r. & n.r. \\
TwinCaps & Multi-unit dose & Capsule & 34 & n.r. & 0.057 \\
Staccato & Single use & Thin drug film & $83-93$ & $1.9-2.2$ & 0.025 \\
Dreamboat & Multi-unit dose & Cartridge & n.r. & n.r. & 0.093 \\
\hline
\end{tabular}

rate of $90 \mathrm{~L} / \mathrm{min}$ (for $2.7 \mathrm{~s}$ ) showed a FPF of $40.3 \pm 5.6 \%(n=4)$ of the dose delivered. Gamma scintigraphic experiments in 12 healthy volunteers showed a lung deposition of $30.1 \pm 7.3 \%$ of the metered dose. Average dose retained in the inhaler was found to be $11.5 \%$ (40). Another study examining the peak inspiratory flow (PIF) through the device in patients suffering from moderate to severe COPD concluded that the examined population, on average, was able to generate enough PIF (92.0 $\pm 15.4 \mathrm{~L} / \mathrm{min}$ ) to reliably inhale the full dose. Additionally, $97 \%$ of performed inhalation maneuvers with the Genuair were shown to be successful (54). Summarizing data from conference presentations, Chrystyn and Niederlaender reported an airflow-independent resistance of $0.031 \mathrm{kPa}^{0.5} \mathrm{~min} / \mathrm{L}$ and a constant delivery of fine particle doses over an inspiratory flow rate range of $45-90 \mathrm{~L} / \mathrm{min}$ (53).

The Genuair inhalation device offers multiple feedback mechanisms to ensure patient compliance, which is important since it is designed to be used on a daily basis for COPD treatment. The fairly low airflow resistance meets the needs of this patient population, and the FPF of about $40 \%$ is state of the art.

\section{Breezhaler}

The Breezhaler, marketed as Neohaler ${ }^{\mathrm{TM}}$ in the USA, has been developed by Novartis (Basel, Switzerland), and is approved for the delivery of indacaterol (a long-acting $\beta$-adrenergic drug) and glycopyrronium bromide (an anticholinergic drug), both indicated for the treatment of COPD. Similar to the Handihaler, it is a single-dose, capsule-based inhaler (see Fig. 1). Prior to inhalation, the patient has to tilt back the mouthpiece and insert a capsule into the device, which is to be pierced by pushing two buttons being located on both sides of the device (55). Piercing the capsule makes an audible clicking sound indicating that the device is primed. Upon inhalation, the capsule makes a whirring noise, which serves as a positive audible feedback control, and indicates that the powder is being inhaled. The patient is advised to verify the correct inhalation by checking on powder remnants in the seethrough capsule (56). Due to its very low airflow resistance of $0.02 \mathrm{kPa}^{0.5} \mathrm{~min} / \mathrm{L}$, the Breezhaler minimizes the effort patients have to make in order to successfully perform the inhalation maneuver, creating independence of the aerosolization performance from the grade of COPD severity or agerelated factors (57). In vitro performance tests conducted with the next generation cascade impactor (NGI) coupled to a flow volume simulator, simulating a patient's breathing pattern, showed an average FPF of $26.8 \pm 5.8 \%$ of the metered dose (150 $\mu \mathrm{g}$ indacaterol). MMAD was found to be $3.2 \pm 0.22 \mu \mathrm{m}$, and the emitted dose (ED) was $68 \pm 9.7 \%$ (58).

Compared to Genuair, the Breezhaler has a lower airflow resistance, which may increase compliance, and therefore safety in COPD therapy. A clinical trial evaluating preference and satisfaction of patients as well as the ease of use of both inhalers (59) has been conducted, with no results published to date. So it remains unclear if the lower reported resistance can translate directly into an overall therapeutic benefit. Audible and visible control feedback mechanisms verify that the dose was primed and inhaled correctly. Since the device is designed as single unit dose device, the need for a dose metering system is negated, making the delivery system more robust when operated correctly, and cheaper to manufacture. On the other hand, carrying the device and blister packs separately might appear to be an additional burden to some patients, especially when traveling.

\section{Podhaler}

The Podhaler device, also known as T-326 inhaler, is designed and marketed to be used with Tobramycin Inhalation Powder (TIPTM) (60). TIP is a particle-engineered tobramycin formulation based on the PulmoSphere ${ }^{\circledR}$ technology, and produced by an emulsion-based spray drying process. Briefly, tobramycin and calcium chloride are incorporated into the outer phase of an emulsion of perfluorooctyl bromide (perflubron) and distearoylphosphatidylcholine in water. Upon spray drying, water and perflubron are removed

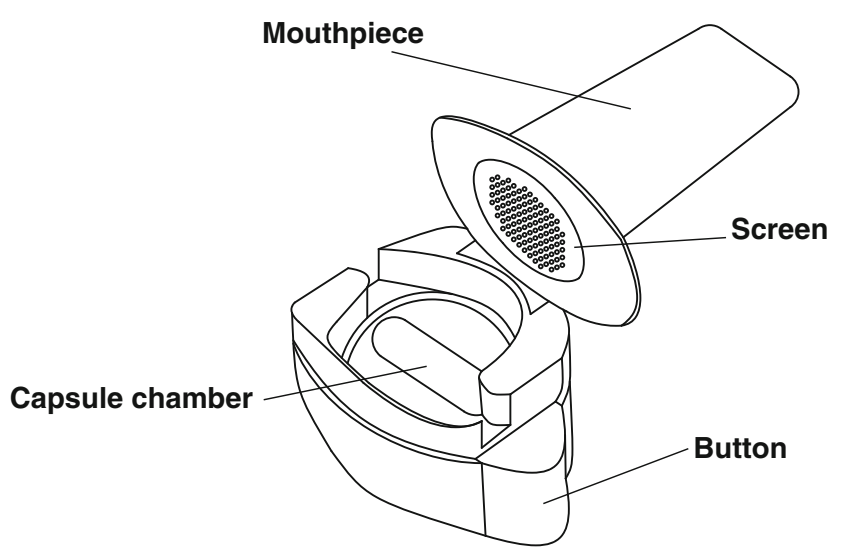

Fig. 1. Schematic diagram of the Breezhaler. Modified from (62) 
subsequently, forming highly porous particles (see Fig. 2) (60), with a drug load as high as $90 \% w / w$ (61). TIP shows good flow and aerosolization properties and can be formulated without the addition of carrier particles. Due to the high dose of tobramycin that needs to be delivered in order to insure an effective therapy, a high drug load is essential to keep the amount of powder to be inhaled low (60).

Based on the Turbospin ${ }^{\circledR}$ device (PH\&T, Milan, Italy), the Podhaler is a capsule-based passive single-unit dose inhaler. To prime the device for inhalation, the patient has to screw off the mouthpiece, insert a TIP capsule, and then replace the mouthpiece. By pressing a plunger on the bottom end of the device, the capsule is pierced twice by a "staple" (see Fig. 3). During inhalation, air is drawn through tangential slots in the capsule chamber putting the capsule into vortical motion, which causes efficient release, aerosolization, and entrainment of the powder (62). The low airflow resistance of about $0.025 \mathrm{kPa}^{0.5} \mathrm{~min} / \mathrm{L}$ (63) and an optimized capsule filling volume contribute to the inhalation maneuver being performed successfully by most patients $(60,62)$. In vitro experiments using the NGI at a pressure drop of $5 \mathrm{kPa}$, that results in a flow rate of $85 \mathrm{~L} / \mathrm{min}$, showed a fine particle dose of $13 \mathrm{mg}$. Each TIP capsule contains $28 \mathrm{mg}$ of tobramycin. Emitted doses at different airflow rates of 40,60 , or $85 \mathrm{~L} / \mathrm{min}$ were found to be $93.5,102$, and $103.2 \%$ of nominal label claimed dose, respectively (63).

Since cystic fibrosis patients face comparable challenges during inspiration as those faced by COPD patients, the low airflow resistance is crucial for their compliance. As indicated previously, the use of TIP instead of TIS is less time consuming, and reduces the risk of patient infection from using a nebulizer that has not been effectively cleaned. Overall, the TOBI dry powder inhalation system might be expected to be highly beneficial for cystic fibrosis patients with persistent Pseudomonas infections, which are not being treated in a hospital setting.

\section{NEXThaler®}

The NEXThaler (Chiesi Farmaceutici, Parma, Italy) is a multidose disposable passive DPI device, which has been approved for the delivery of a combination of formoterol fumarate and beclomethasone dipropionate. In this device,

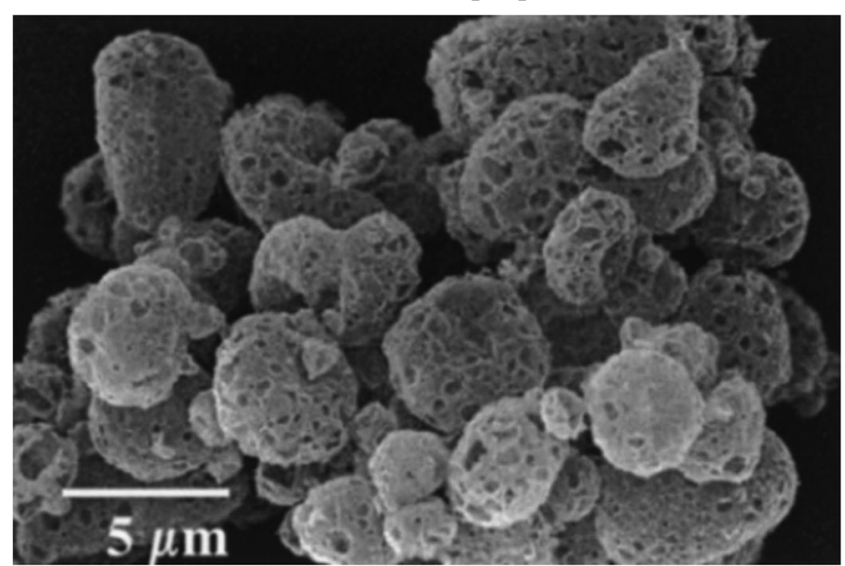

Fig. 2. SEM image of PulmoSphere particles. Reproduced from Pharmaceutical Research with kind permission from Springer Science + Business Media the dry powder formulation has protection from environmental influences, such as humidity, by a desiccant, which is placed adjacent to the powder reservoir and separated by a semipermeable membrane. A chamfer at the front edge of the reservoir ensures that the powder is uniformly dispensed into the dosing cup. This process is reported to improve the reproducibility of the dosing (64). In order to prime the device, the patient must first open the mouthpiece cover. The integrated dose counter advances when the mouthpiece cover is closed (65), but only if the metered dose has been inhaled. The dose is released when the breath actuation system measures an inspiratory flow corresponding to a pressure drop of $1.5 \mathrm{kPa}$ (64). The inspiratory flow resistance of $0.036 \mathrm{kPa}^{0.5} \mathrm{~min} / \mathrm{L}$ is intermediate, and requires an inspirational effort comparable to inhalation with the Diskus ${ }^{\circledR}$ or Turbuhaler ${ }^{\circledR}$. In vitro experiments using the NGI at flow rates of 30 and $90 \mathrm{~L} / \mathrm{min}$ show high FPFs of 54.5 and $67.6 \%$, respectively (66).

Though the NEXThaler device is probably the most easy to use device presented in this section, it offers audible and visible feedback control mechanisms, indicating that the dose was inhaled correctly. It might be a concern that a more visible control mechanism would have been desirable, since the patient must be aware of how many doses are left before and following inhalation. This visualization issue might be a safety concern particularly in older patient populations. Since the inspiratory capacities of patients using this inhaler might be compromised, a lower airflow resistance would also be desirable. However, one should bear in mind that FPFs of more than $50 \%$ are a great improvement in comparison to the older DPI models.

\section{Dreamboat}

The Dreamboat (MannKind Corp., Valencia, CA, USA) inhaler is a reusable multi-unit dose inhalation device, which has been approved for the delivery of recombinant rapid acting prandial insulin using MannKind's proprietary TechnoSphere technology. TechnoSpheres are engineered particles consisting of a novel excipient-fumaryl diketopiperazine (FDKP). FDKP is highly water soluble at $\mathrm{pH}>6$ (67) but precipitates into microcrystalline platelets, which agglomerate, and form low density particles at acidic conditions. Insulin or other peptides present in solution are entrapped during the self-assembly process (68). In order to form a dry powder, suspensions need to be dried by a suitable method, e.g., freeze-drying (69). Resulting particles are reported to have a geometrical diameter of $1-10 \mu \mathrm{m}$ $(67,70,71)$, high internal porosity and surface area (71), and can be administered without the addition of carrier particles. In order to inhale a dose, the patient has to insert a premetered plastic cartridge, containing a dose of either 4 or 8 international units of insulin, into the device, close it, inhale, and remove the cartridge afterwards. Since doses in diabetes therapy are to be determined individually, multiple inhalation maneuvers must be conducted subsequently to deliver the dose needed. The number of cartridges to be inhaled can be determined using a dose conversion table given in the prescribing information (51). In order to avoid application of erroneous doses, the cartridges are color coded, and cartridges already used are visually distinguishable from the ones unused. In earlier development stages and during pivotal clinical 


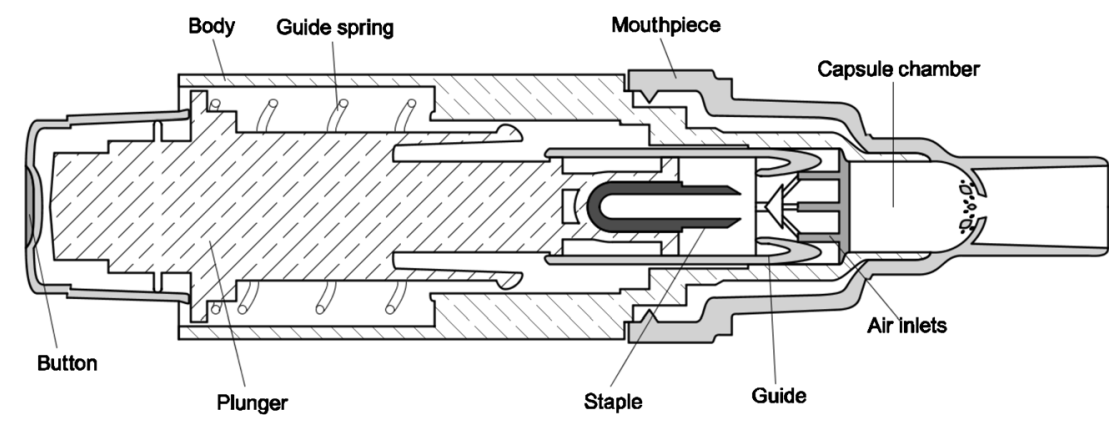

Fig. 3. Cross-sectional view of the Podhaler device. Modified from (62)

trials, MannKind used its also proprietary MedTone ${ }^{\mathrm{TM}}$ inhaler but switched to the Dreamboat due to its smaller size, more appealing design, and its capability to deliver equivalent doses at a lower cartridge load $(50,72)$. The Dreamboat inhaler deagglomerates the powder in a convergence zone where two independent flow paths intersect. One inlet stream enters the device at the cartridge, fluidizing and entraining the powder, whereas another inlet stream enters from the rear end of the mouthpiece (see Fig. 4) (73). The inhaler is reported to have a high resistance of about $0.093 \mathrm{kPa}^{0.5} \mathrm{~min} / \mathrm{L}$ (67). Since subpopulations with impaired lung function, i.e., patients suffering from obstructive diseases such as asthma or COPD as well as smokers, are excluded from using Afrezza (51), qualified populations can be expected to generate sufficient inspiratory flow. Predominant features of the Dreamboat inhaler are its size and design, as well as its intuitive operation. It lacks visible or audible feedback that the dose was inhaled correctly as well as a visible verification that the amount needed was inhaled. Pulmonary application from a small device resembling an asthma inhaler surely makes the therapy more discrete, which can be advantageous in public settings, and might improve the patient's quality of life. After the withdrawal of Pfizer's Exubera ${ }^{\circledR}$ in 2008, Afrezza now is the second attempt to market an inhalable insulin formulation. By now, it remains unclear if Afrezza will become more successful than its precursor, but this approach has some potential to improve the quality and tolerability of insulin therapy.

\section{DISPOSABLE SINGLE-USE DPIS}

Most DPI devices are developed and marketed for the treatment of chronic airway diseases such as COPD and asthma, and, besides the general requirements mentioned above, they are optimized in terms of cost effectiveness, and to increase patient compliance and adherence to their routine medication (22). Apart from these well-established applications, DPIs are also a suitable option for therapeutic or prophylactic interventions that might require a lower frequency of drug intake (74-76). Though not being a disposable single-use inhaler, GSK's Diskhaler® (Glaxo Wellcome/GSK, Brentford, UK), which has already been discussed elsewhere $(15,43)$, is to be mentioned as the first device being approved for inhalable anti-infectious therapy. It initially gained FDA approval for the administration of zanamivir, the first clinically available neuramidase inhibitor, for treatment of influenza A and B virus infections in 1999, which was extended to prophylactic treatment in 2006 (77). Having received authorization for the Japanese market in 2010, the TwinCaps ${ }^{\circledR}$ inhaler (Hovione, Loures, Portugal) was the first disposable singleuse DPI device to be approved. It is used for the delivery of laninamivir, a novel neuramidase inhibitor indicated for the treatment and postexposure prophylaxis of influenza A and B virus infections. Patients suffering from other infectious airway diseases, e.g., cystic fibrosis-related Pseudomonas infections or pulmonary aspergillosis, could also benefit from using disposable, as opposed to reusable DPIs or nebulizers, to minimize the risk of recurrent infections. Similar considerations could apply to inhaled cancer therapies, minimizing the risk of unwanted exposure to highly cytotoxic drugs (64). Additionally, disposable DPIs could also offer a superior way of delivering vaccines (78). Vaccine formulations contain antigens such as proteins, peptides, and polysaccharides, or attenuated bacteria, viruses, or parasites to induce a specific immunological response (79). Since they are prone to degradation and show poor absorption and bioavailability when administered via the oral route, most modern vaccine formulations are administered parenterally as intramuscular or subcutaneous injections (80). However, application by injection requires trained medicinal personnel and involves the risk of needle-stick injuries and transmission of blood-borne infections. Due to stability issues, most vaccine formulations require uninterrupted refrigerated storage conditions (81).

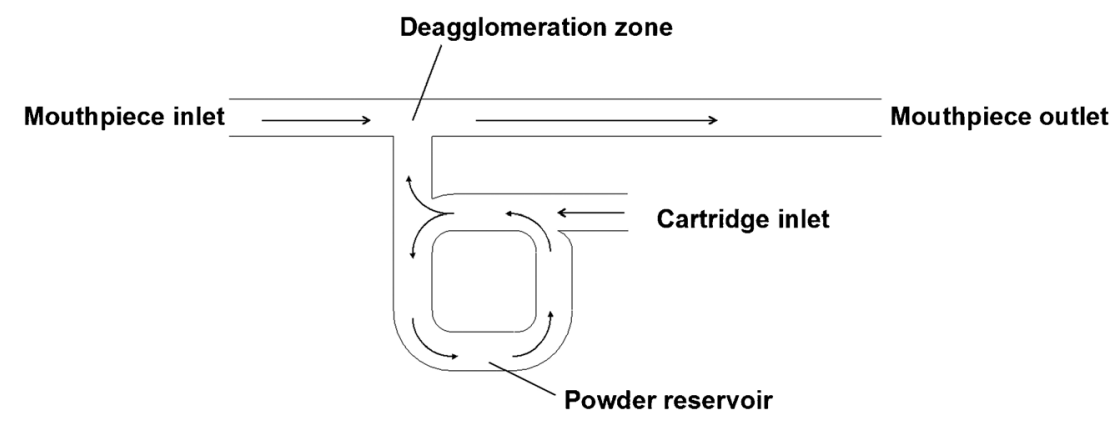

Fig. 4. Schematic diagram of the flow path in the Dreamboat device. Modified from (73) 
There is an increased strain on developing countries that have a high demand/need for updating their vaccination programs (82), and do often not meet some of the aforementioned requirements. Dry powder formulations offer a noninvasive route of delivery as well as improved stability upon storage and transport. Another possible field of application for disposable DPIs is in the use in rescue medication. Though not strictly being a dry powder inhaler, FDA and European Medicines Agency (EMA) approval of the Staccato ${ }^{\circledR}$ device (Alexza, Mountain View, CA, USA) in 2012/2013 confirms the feasibility of this concept. It has been approved for the delivery of loxapine, a dibenzoxapine antipsychotic drug indicated for the treatment of agitation related to acute schizophrenic episodes and bipolar I disorders (20). Other possible applications as rescue medicine would be in acute pain management (74), migraine (83), and Parkinson's disease (84). As mentioned earlier in this section, single-use disposable DPIs have to meet different requirements than reusable ones. The need for an effective dose metering system is however negated. Since the disposable DPI itself can be packed and sealed, it is therefore not exposed to direct environmental conditions such as humidity, so there may be no need to ensure a high level of protection of the drug within the DPI. Patients potentially using disposable DPIs cannot be expected to be familiar with medical inhalation devices, so it is preferable to keep operation of the device as simple as possible. Visible or audible control feedback mechanisms would be a great benefit to naive patients. Of course, it is compulsory for disposable devices to meet all the requirements necessary to ensure a safe therapy, i.e., dose accuracy and reproducibility (23).

\section{Twincer®}

The breath-actuated Twincer device is designed to efficiently deliver high doses of non-particle-engineered dry powders, producing a high fine particle fraction at a low airflow resistance (85). It consists of three plate-like plastic parts forming airflow passages and either a blister chamber or a drug compartment. Connection of the dose compartment to a powder channel is established by either removing a folded plastic foil from the blister or actuating a slide (86). Powder deagglomeration is achieved by two tangentially arranged air classifiers utilizing the same principle that is present in the Novolizer device (as mentioned above). However, the number of tangential air channels is reduced in this device (see Fig. 5). In vitro experiments show a good performance of particle deagglomeration, compared to the Turbuhaler device. Particle size distributions of aerosolized colistin sulfomethate were found to be similar in a dose range from 0 to $25 \mathrm{mg}$ using different models of the Twincer, optimized for the specific drug load. Multistage impactor experiments at flow rates of 30 and $60 \mathrm{~L} / \mathrm{min}$ determined FPFs of approximately $40 \%$ and $52-60 \%$ (depending on the model), respectively (85). Another study using a four-stage liquid impinger reported the FPF of spray- or spray-freeze dried monovalent influenza vaccine/inulin particles to be 37 and $23 \%$, respectively (88).

Since the Twincer can be loaded with fairly large amounts of powders, it is an interesting candidate for the application of e.g., antibiotics or other APIs requiring high doses. In a make developed for market entry, visible and/or audible feedback control mechanisms would be desirable, but one must notice that this device is still under development.

\section{Conix $^{\mathrm{TM}}$}

The Conix drug delivery platform (3M, St. Paul, MN, USA) is available as single-dose reusable, single-dose disposable, and multidose DPI device. To deagglomerate the powder formulation, it utilizes a reverse cyclone. Upon actuation, air and powder enter a conic chamber creating a free vortex. Different from a regular cyclone separator, the bottom of the chamber is closed, forcing the vortex to reverse the flow creating a second vortex in the center that exits from an orifice in the lid (see Fig. 6). This design is reported to achieve relatively high velocities in the vortex resulting in an efficient deagglomeration (89). Carrier particles are retained within the cyclone reducing the amount of powder impacting in the patient's throat or upper airways (90). In vitro experiments investigating the performance of the Conix to aerosolize salbutamol powder formulations extracted from the Accuhaler® (GSK, Brentford, UK) using an Andersen cascade impactor report a FPF of $85 \%$ and an ED of slightly more than $60 \%$ (89). This high FPF is related to the retention of carrier particles within the reverse cyclone separator. This retention of powders is not problematic for a single-dose disposable unit; however, it should be noted that this type of carrier particle retention would be considered detrimental to the performance of a multidose type device.

\section{TwinCaps}

As mentioned above, the TwinCaps (Hovione, Loures, Portugal) inhalation device is a multi unit dose inhaler, designed to be marketed as prefilled, low-cost inhaler to deliver large doses (91). In 2010, it gained approval in Japan for the delivery of laninamivir, a novel neuramidase inhibitor for the treatment and postexposure prophylaxis of influenza A and B virus infections, and was marketed as Inavir ${ }^{\circledR}$ (Daiichi Sankyo, Tokyo, Japan). As shown in Fig. 7, the inhaler consists of two plastic parts, of which the dose compartment housing is moveable. It contains two separate compartments, offering protection of the powder formulation from most environmental influences when closed. To prime the device, the patient is required to slide the housing to either side, aligning the dose compartment with the air channel by pushing one of the two buttons being placed on both sides of the device. After inhaling the first dose, the housing slides to the opposite side, and the second dose compartment becomes accessible. Upon inhalation, a turbulent airflow in the compartment is created, entraining and deagglomerating the powder (23). In vitro experiments aerosolizing a lactose-based model carrier formulation using an Andersen cascade impactor operated at a pressure drop of $4 \mathrm{kPa}$ demonstrated a FPF of $34 \%$ and an ED of $35 \%$. Resistance is reported to be $0.057 \mathrm{kPa}^{0.5} \mathrm{~min} / \mathrm{L}$ (92), and can therefore be evaluated as intermediate. Due to the high drug loading capacity, the TwinCaps device, similar to the Twincer, is an interesting future option for the delivery of high doses. 


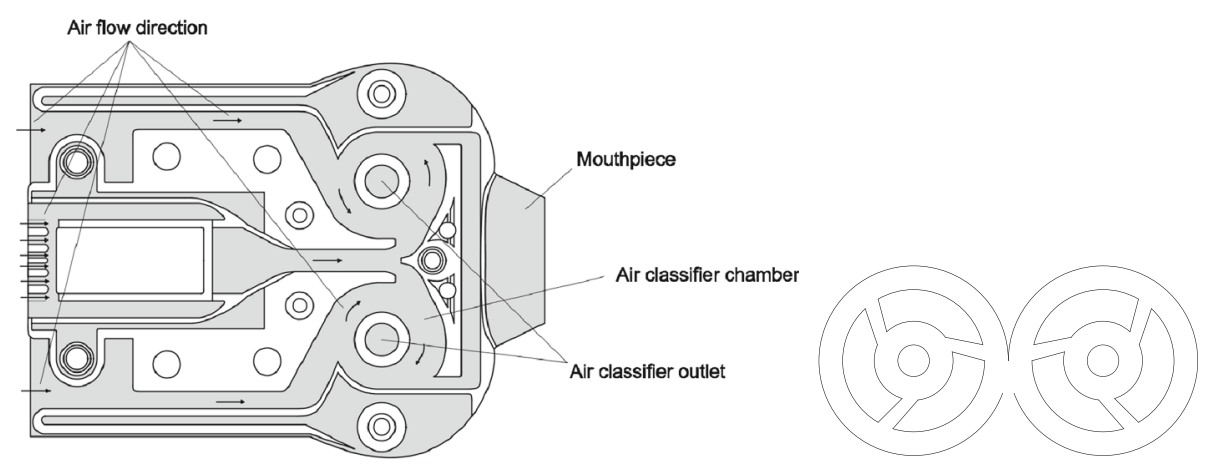

Fig. 5. Cross-sectional view (left) and detailed view (right) on the air classifiers of the Twincer device. Modified from $(23,87)$

\section{Staccato}

Though not being a classical dry powder inhaler, the Staccato device (Alexza Pharmaceuticals, Mountain View, CA, USA) is a highly interesting disposable single-use inhalation device, and, as such, it will be discussed in this section. As mentioned earlier, it was approved by FDA and EMA for the delivery of loxapine marketed as Adasuve ${ }^{\circledR}$ (Teva North America, North Wales, PA, USA). It establishes aerosolization of respirable solid-state particles not by deagglomerating a preformulated dry powder but by resublimation of vaporized drug in situ (93). It consists of a heat package and a breath sensor in a polypropylene housing (see Fig. 8). To prime the device, the patient has to remove a tab on the rear end and a green display light indicates when it is ready to be actuated (94). The heat package is coated with a $1-10 \mu \mathrm{m}$-thick drug film in the dry state, corresponding to a dose of 5 or $10 \mathrm{mg}$, which is vaporized upon breath actuation. The breath sensor is coupled to the heat package, and triggers a chemical reaction causing the heat package to heat up to about $400^{\circ} \mathrm{C}$ within approximately $0.2 \mathrm{~s}$ when inspiratory airflow from the patient is detected (95). Vaporized drug resublimates into distinct aerosolized particles within a respirable size range, to be subsequently entrained by the airflow. Size distribution of the resublimated particles is controlled by the airflow velocity over the vaporizing compound (96). Even though the device locally generates high temperatures, it was shown that the peak wet bulb temperature of the outlet stream of 39.9 $\pm 0.1^{\circ} \mathrm{C}$, determined in a worst-case scenario setup, is well below the recommended standard of $50^{\circ} \mathrm{C}$ (97). In vitro experiments using the NGI at a flow rate of $30 \mathrm{~L} / \mathrm{min}$ showed an ED of $89-102 \%$ depending on the preoperating stress

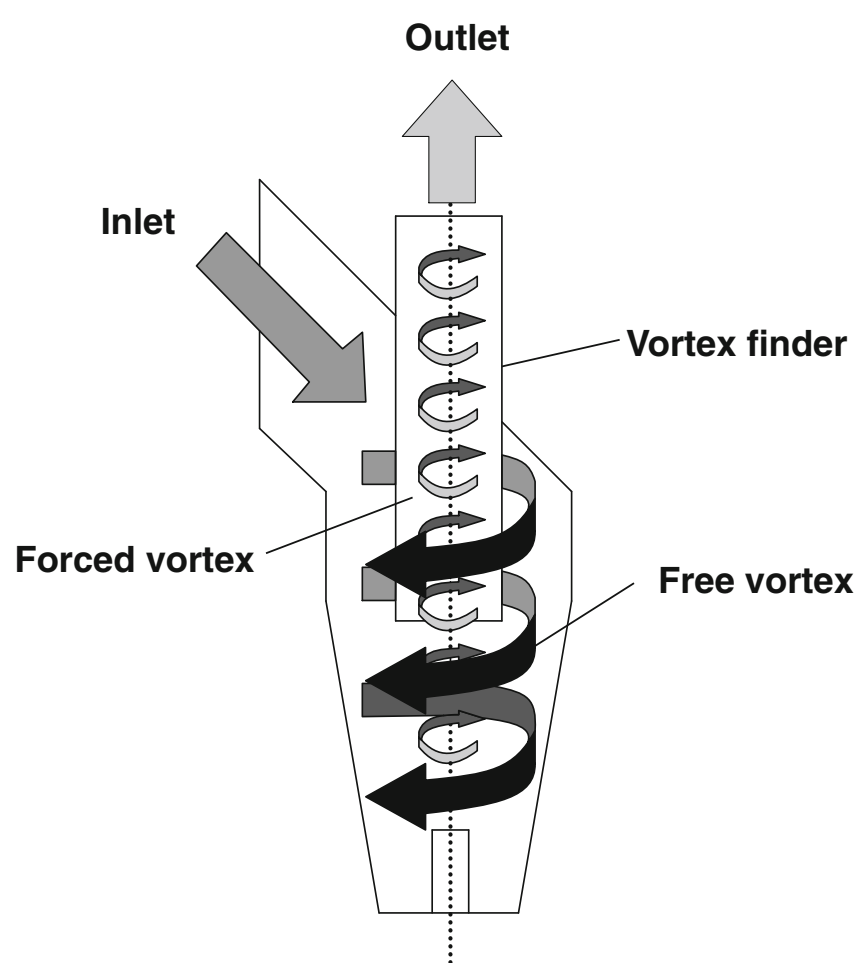

Fig. 6. Schematic of the reverse cyclone technology used in the Conix device. Modified from (89) 


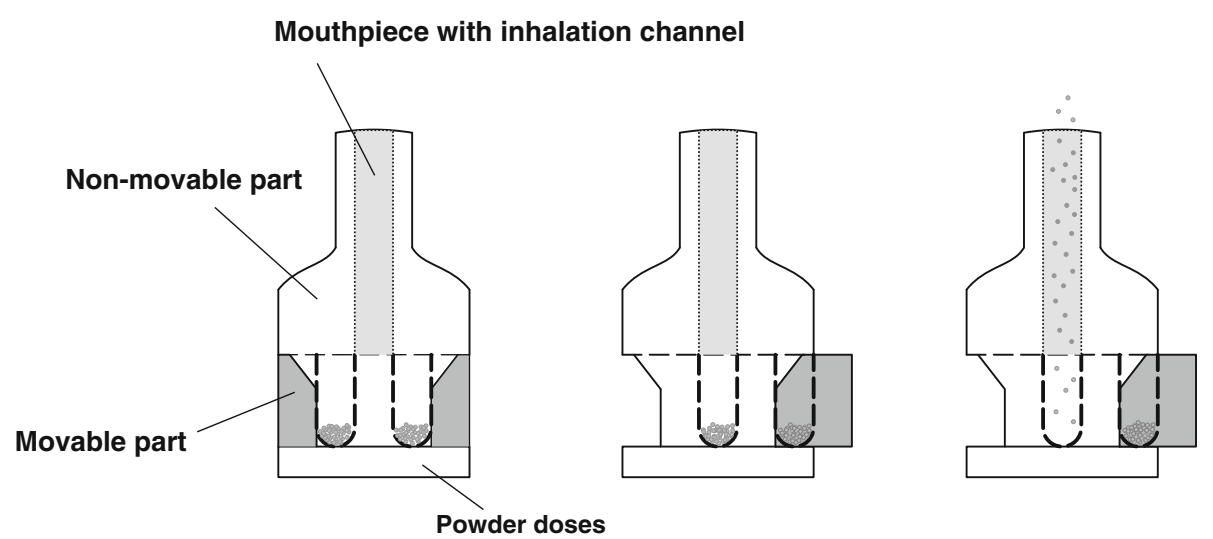

Fig. 7. Schematic diagram of the sealed (left), primed (middle), and actuated (right) TwinCaps device. Modified from (24)

conditions applied. FPF ranged from 83 to $93 \%$, and the MMAD from 1.9 to $2.2 \mu \mathrm{m}$. Variation of the flow rate to 15 and $45 \mathrm{~L} / \mathrm{min}$ showed a MMAD of 2.8 and $1.7 \mu \mathrm{m}$, respectively (95), demonstrating independence from the inspiratory performance of the patient. Inspiratory flow resistance is reported as approximately $0.025 \mathrm{kPa}^{0.5} \mathrm{~min} / \mathrm{L}(98,99)$, and can be evaluated as low. In vitro experiments using an oropharyngeal geometry model verified that about $90 \%$ of the emitted dose is in a size range sufficiently small to reach the lower airways (98). In vitro and in vivo studies showed a high consistency in the dose effectively delivered (99), and confirm a rapid uptake of the drug (100). Feasibility of the Staccato device in other therapeutic fields, e.g., acute pain management or smoking cessation, is also being investigated $(101,102)$. According to Alexza's product pipeline Staccato fentanyl is being developed as a multidose device $(99,103)$. Due to the mechanism used to generate the aerosol particles, this device is limited to the application of highly potent drugs, which are not prone to degradation upon heating.

\section{Other Notable Devices}

The ResQhalerTM (Aespira Ltd., Moshav Shdema, Israel) is a disposable, breath-actuated dry powder inhaler featuring an audible control feedback mechanism. It utilizes the company’s proprietary ActiveMesh $₫$ technology. Dry powder formulations are stored in a mesh-like package releasing particles in the respirable range upon breath-driven beating of the container (104).

The TrivAirTM (Trimel Pharmaceuticals, Mississauga, Canada), formerly known as DirectHaler ${ }^{\mathrm{TM}}$, is a disposable dry powder inhaler for pulmonary and nasal delivery. It consists of a U-shaped inhaler tube with a corrugated bend, which serves as deagglomeration zone (23). In 2010, Trimel started a phase II clinical trial for dose finding of salbutamol sulfate in intermittent or persistent mild asthma patients. The status of this trial is unknown (105).

The Cricket ${ }^{\mathrm{TM}}$ inhaler (MannKind Corp., Valencia, CA, USA) is the single-use disposable version of the Dreamboat inhaler, which was designed to be used with the company's proprietary TechnoSphere technology, and has already been discussed in a previous section (106).

Occoris ${ }^{\circledR}$ (Team Consulting, Cambridge, UK) is an active powder aerosolization engine to be incorporated into singledose reusable and disposable or multidose inhalers. It is designed to aerosolize unformulated powders, and the manufacturer highlights the high performance while still being a lowcost device (107).

Another inhaler has been developed by Manta Devices (Cambridge, MA, USA). For priming the device, it has to be popped out from a blister offering environmental protection (108).

\section{CONCLUSION}

During the past five decades, dry powder inhalation became widely available, and has an established key position in the treatment of respiratory diseases. The field has expanded to include not only local therapy for obstructive pulmonary diseases, but also systemic delivery of compounds requiring parenteral application or regimens that might require a fast onset for the desired therapeutic effect. The availability of

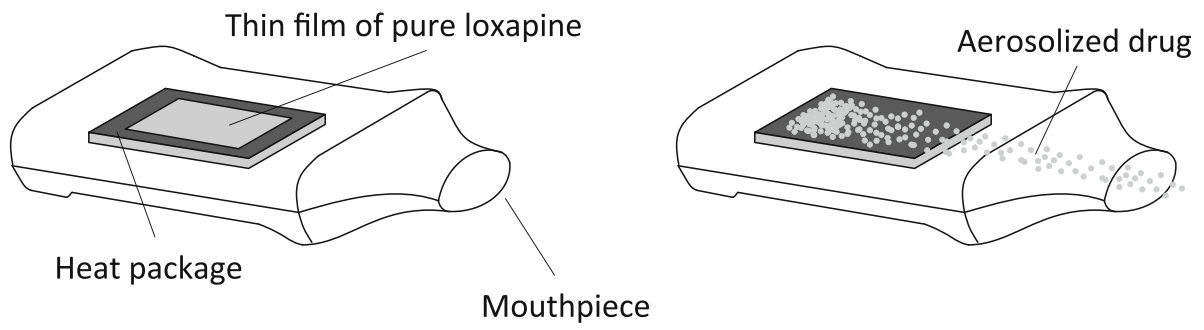

Fig. 8. Schematic diagram of the Staccato loxapine device. Modified from (93) 
reliable, cheap, and convenient single-use dry powder inhalation devices could be influential in the development of future vaccination strategies and is likely to become increasingly important in the therapy of respiratory infections.

\section{ACKNOWLEDGMENTS}

The authors would like to thank Elena Macchi and Amber McBride for their kind support.

\section{REFERENCES}

1. Crompton G. A brief history of inhaled asthma therapy over the last fifty years. Prim Care Respir J. 2006;15(6):326-31.

2. Molina MJ, Rowland FS. Stratospheric sink for chlorofluoromethanes: chlorine atom-catalysed destruction of ozone. Nature. 1974;249:810-2.

3. UNEP. The Montreal Protocol on substances that deplete the ozone layer. http://ozone.unep.org/pdfs/Montreal-Protocol2000.pdf. Accessed 22 Feb 2014.

4. Department of Health and Human Services. Use of ozonedepleting substances; removal of essential use designations. Fed Regist. 2005;70(63):17167-92.

5. Department of Health and Human Services. Use of ozonedepleting substances; removal of essential use designations (flunisolide etc.). Fed Regist. 2010;75(71):19213-41.

6. Myrdal PB, Sheth P, Stein SW. Advances in metered dose inhaler technology: formulation development. AAPS PharmSciTech. 2014;15(2):434-55.

7. Sanders M. Inhalation therapy: an historical review. Prim Care Respir J. 2007;16(2):71-81.

8. McDonald KJ, Martin GP. Transition to CFC-free metered dose inhalers - into the new millennium. Int J Pharm. 2000;201(1):89-107.

9. Oenbrink RJ. Unexpected adverse effects of Freon 11 and Freon 12 as medication propellants. J Am Osteopath Assoc. 1993;93(6):714-8.

10. Bryant DH, Pepys J. Bronchial reactions to aerosol inhalant vehicle. Br Med J. 1976;1(6021):1319-20.

11. Smyth HDC. The influence of formulation variables on the performance of alternative propellant-driven metered dose inhalers. Adv Drug Deliv Rev. 2003;55(7):807-28.

12. Soine WH, Blondino FE, Byron PR. Chemical stability in pressurized inhalers formulated as solutions. J Biopharm Sci. 1992;3(1):41-7.

13. Philips EM, Byron PR. Surfactant promoted crystal growth of micronized methylprednisolone in trichloromonofluoromethane. Int J Pharm. 1994;110(1):9-19.

14. Johnson KA. Interfacial phenomena and phase behavior in metered-dose inhaler formulations. In: Hickey AJ, editor. Inhalation aerosols (94). New York: Marcel Dekker; 1996. pp. 385-415.

15. Son YJ, McConville JT. Advancements in dry powder delivery to the lung. Drug Dev Ind Pharm. 2008;34(9):948-59.

16. O'Connor BJ. The ideal inhaler: design and characteristics to improve outcomes. Respir Med. 2004;98(Suppl A):10-6.

17. Stein SW, Sheth P, Hodson PD, Myrdal PB. Advances in metered dose inhaler technology: hardware development. AAPS PharmSciTech. 2014;15(2):326-38.

18. Clark AR. Medical aerosol inhaler: past, present, and future. Aerosol Sci Technol. 1995;22(4):374-91.

19. Barnes PJ, Stockley RA. COPD: current therapeutic interventions and future approaches. Eur Respir J. 2005;25(6):1084-106.

20. Keating GM. Loxapine inhalation powder: a review of its use in the acute treatment of agitation in patients with bipolar disorder or schizophrenia. CNS Drugs. 2013;27(6):479-89.

21. Riley A, Main M, Morgan F. Inhalation device allows novel administration of apomorphine in men with erectile dysfunction - efficacy and safety findings. J Sex Med. 2010;7(4 Pt 1):1508-17.

22. Siekmeier R, Scheuch G. Inhaled insulin - does it become reality? J Physiol Pharmacol. 2008;59 suppl 6:81-113.
23. Friebel C, Steckel H. Single-use disposable dry powder inhalers for pulmonary drug delivery. Expert Opin Drug Deliv. 2010;7(12):1359-72.

24. Labiris NR, Dolovich MB. Part I: physiological factors affecting therapeutic effectiveness of aerosolized medications. Br J Clin Pharmacol. 2003;56(6):588-99.

25. Vanbever R, Mintzes JD, Wang J, et al. Formulation and physical characterization of large porous particles for inhalation. Pharm Res. 1999;16(11):1735-42.

26. Telko MJ, Hickey AJ. Dry powder inhaler formulation. Respir Care. 2005;50(9):1209-27.

27. Dunbar CA, Hickey AJ, Holzner P. Dispersion and characterization of pharmaceutical dry powder aerosols. Kona Powder Part J. 1998;16:7-45.

28. Young PM, Sung A, Traini D, Kwok P, Chiou H, Chan HK. Influence of humidity on the electrostatic charge and aerosol performance of dry powder inhaler carrier based systems. Pharm Res. 2007;24(5):963-70.

29. Chow AHL, Tong HHY, Chattopadhyay P, Shekunov BY. Particle engineering for pulmonary drug delivery. Pharm Res. 2007;24(3):411-37.

30. Voss A, Finlay WH. Deagglomeration of dry powder pharmaceutical aerosols. Int J Pharm. 2002;248(1-2):39-50.

31. Clark AR, Hollingworth AM. The relationship between powder inhaler resistance and peak inspiratory conditions in healthy volunteers - implications for in vitro testing. J Aerosol Med. 1993;6(2):99-110.

32. Tiddens, Geller DE, Challoner P, et al. Effect of dry powder inhaler resistance on the inspiratory flow rates and volumes of cystic fibrosis patients of six years and older. J Aerosol Med. 2006;19(4):456-65.

33. Feddah MR, Brown KF, Gipps EM, Davies NM. In-vitro characterisation of metered dose inhaler versus dry powder inhaler glucocorticoid products: influence of inspiratory flow rates. J Pharm Pharm Sci. 2000;3(3):318-24.

34. Chan JGY, Wong J, Zhou QT, Leung SSY, Chan H-K. Advances in device and formulation technologies for pulmonary drug delivery. AAPS PharmSciTech. 2014;15(4):882-97.

35. Timsina MP, Martin GP, Marriott C, Ganderton D, Yianneskis M. Drug delivery to the respiratory tract using dry powder inhalers. Int J Pharm. 1994;101(1-2):1-13.

36. Bisgaard H. Delivery of inhaled medication to children. J Asthma. 1997;34(6):443-67.

37. Zainudin BM, Biddiscombe M, Tolfree SE, Short M, Spiro SG. Comparison of bronchodilator responses and deposition patterns of powder, and as a nebulised solution. Thorax. 1990;45(6):469-73.

38. Richards R, Dickson CR, Renwick AG, Lewis RA, Holgate ST. Absorption and disposition kinetics of cromolyn sodium and the influence of inhalation technique. J Pharmacol Exp Ther. 1987;241(3):1028-32.

39. Chodosh S, Flanders JS, Kesten S, Serby CW, Hochrainer D, Witek Jr TJ. Effective delivery of particles with the HandiHaler dry powder inhalation system over a range of chronic obstructive pulmonary disease severity. J Aerosol Med. 2001;14(3):309-15.

40. Newman SP, Sutton DJ, Segarra R, Lamarca R, de Miquel G. Lung deposition of aclidinium bromide from Genuair, a multidose dry powder inhaler. Respiration. 2009;78(3):322-8.

41. Islam N, Cleary MJ. Developing an efficient and reliable dry powder inhaler for pulmonary drug delivery - a review for multidisciplinary researchers. Med Eng Phys. 2012;34(4):409-27.

42. Claus S, Weiler C, Schiewe J, Friess W. How can we bring high drug doses to the lung? Eur J Pharm Biopharm. 2014;86(1):1-6.

43. Smith IJ, Parry-Billings M. The inhalers of the future? A review of dry powder devices on the market today. Pulm Pharmcol Ther. 2003;16(2):79-95.

44. Islam N, Gladki E. Dry powder inhalers (DPIs) - a review of device reliability and innovation. Int J Pharm. 2008;360(1-2):1-11.

45. Yadav N, Lohani A. Dry powder inhalers: a review. IGJPS. 2013;3(2):142-53.

46. Blau H, Mussaffi H, Mei Zahav M, Prais D, Livne M, Czitron $\mathrm{BM}$, et al. Microbial contamination of nebulizers in the home treatment of cystic fibrosis. Child Care Health Dev. 2007;33(4):491-5. 
47. VanDevanter DR, Geller DE. Tobramycin administered by the TOBI ${ }^{\circledR}$ podhaler for persons with cystic fibrosis: a review. Med Devices. 2011;4:179-88.

48. Konstan MW, Flume PA, Kappler M et al. Safety, efficacy and convenience of tobramycin inhalation powder in cystic fibrosis patients: the EAGER trial. J Cyst Fibros. 2011;10(1):54-61.

49. Harsch IA, Hahn EG, Konturek PC. Syringe, pen, inhaler - the evolution of insulin therapy. Med Sci Monit. 2001;7(4):833-36.

50. Kling J. Dreamboat sinks prospects for fast approval of inhaled insulin. Nat Biotechnol. 2011;29(3):175-6.

51. drugs@FDA database. Food and drug administration. http:// www.accessdata.fda.gov. Accessed 20 Dec 2014

52. drugs@FDA database. Food and drug administration. http:// www.accessdata.fda.gov. Accessed 11 Dec 2013.

53. Chrystyn H, Niederlaender C. The Genuair inhaler: a novel, multidose dry powder inhaler. Int J Clin Pract. 2012;66(3):309-17.

54. Magnussen H, Watz H, Zimmermann I, Macht S, Greguletz R, Falques M, et al. Peak inspiratory flow through the Genuaira inhaler in patients with moderate or severe COPD. Respir Med. 2009;103(12):1832-7.

55. Buhl R, Banerij D. Profile of glycopyrronium for once-daily treatment of moderate-to-severe COPD. Int J Chron Obstruct Pulmon Dis. 2012;7:729-41.

56. Arcapta medication guide. Novartis, Basel, Switzerland. http:// www.fda.gov. Accessed 6 Jan 2014.

57. Pavkov R, Mueller S, Fiebich K, et al. Characteristics of a new capsule based dry powder inhaler for the effective delivery of indacaterol. Curr Med Res Opin. 2010;26(11):2527-33.

58. Chapman KR, Fogarty CM, Peckitt C, et al. Delivery characteristics and patients' handling of two single-dose dry powder inhalers used in COPD. Int J Chron Obstruct Pulmon Dis. 2011;6:353-63.

59. Clinicaltrials.gov database, ID: NCT01915784. NIH. http:// www.clinicaltrials.gov. Accessed 20 Feb 2014

60. Geller DE, Weers J, Heuerding S. Development of an inhaled dry powder formulation of tobramycin using PulmoSphere technology. J Aerosol Med Pulm Drug Deliv. 2011;24(4):175-82.

61. Newhouse MT, Hirst PH, Duddu SP, Walter YH, Tarara TE, Clark AR, et al. Inhalation of a dry powder tobramycin PulmoSphere formulation in healthy volunteers. Chest. 2003;124(1):360-6.

62. Maltz DS, Paboojian SJ. Device engineering insights into TOBI Podhaler: a development case study of high efficient powder delivery to cystic fibrosis patients. In: Dalby RN, Byron PR, Peart J, Suman JD, Young PM, editors. Proceedings of RDD Europe 2011. River Grove: Davis Healthcare International Publication; 2011. pp. 55-65.

63. Haynes A, Nakamura J, Heng C, Heuerding S, Thompson G, Malcolmson R. Aerosol performance of tobramycin inhalation powder. In: Dalby RN, Byron PR, Peart J, Suman JD, Farr SJ, Young PM, editors. Proceedings of RDD 2010. River Grove: Davis Healthcare International Publication; 2010. pp. 701-6.

64. Brambilla G, Coconi D, Armanni A, Smith S, Lye E, Burge S. Designing a novel dry powder inhaler: the NEXT DPI (part 1). In: Dalby RN, Byron PR, Peart J, Suman JD, Farr SJ, Young PM, editors. Proceedings of RDD 2006. River Grove: Davis Healthcare International Publication; 2006; pp. 553-6.

65. Chiesi Farmaceutici, Parma, Italy. Fachinfo Foster (medication guide, GER). http://www.fachinfo.de/. Accessed 9 Jan 2014.

66. Pasquali I, Brambilla G, Copelli D. Effect of flow rate on dose delivery of three dry powder inhalers: NEXThaler, Turbohaler and Diskus. In: Dalby RN, Byron PR, Peart J, Suman JD, Farr SJ, Young PM, editors. Proceedings of RDD 2013. River Grove: Davis Healthcare International Publication; 2013. pp. 267-72.

67. Leone-Bay A, Baughman R, Smutney C, Kocinsky J. Innovation in drug delivery by inhalation. On Drug Deliv. 2010;4(7):4-8.

68. Kaur N, Zhou B, Breitbeil F, Hardy K, Kraft KS, Trantcheva I, et al. A delineation of diketopiperazine self-assembly processes. Understanding the molecular events involved in $\mathrm{N}^{\varepsilon}$ (fumaroyl)diketopiperazine of L-Lys (FDKP) interactions. Mol Pharm. 2008;5(2):294-315.

69. Pfützner A, Forst T. Pulmonary insulin delivery by means of Technosphere drug carrier mechanism. Expert Opin Drug Deliv. 2005;2(6):1097-106.
70. Soares S, Costa A, Sarmento B. Novel non-invasive methods of insulin delivery. Expert Opin Drug Deliv. 2012;9(12):1539-58.

71. Angelo R, Rousseau K, Grant M, Leone-Bay A, Richardson P. Technosphere ${ }^{\circledR}$ insulin: defining the role of Technosphere particles at cellular level. J Diabetes Sci Technol. 2009;3(3):545-54.

72. Marino MT, Cassidy JP. The relationship between two insulin assays used to determine bioequivalence and dose proportionality of Afrezza insulin administered using a gen2 inhaler compared to a MedTone inhaler: simulation of clinical trials and actual data. Poster presented at: Diabetes Technology Meeting 2010 Nov 11-13. Bethesda, MD, USA.

73. Leone-Bay A, Smutney C, Kocinsky J. Pulmonary drug delivery_simplified. OnDrugDeliv. 2011;5(5):18-21.

74. Gagnadoux F, Hureaux J, Vecellio L, et al. Aerosolized chemotherapy. J Aerosol Med Pulm Drug Deliv. 2008;21(1):61-70.

75. Sullivan VJ, Mikszta JA, Laurent P, Huang J, Ford B. Noninvasive delivery technologies: respiratory delivery of vaccines. Expert Opin Drug Deliv. 2006;3(1):87-95.

76. Worsley MH, Macleod AD, Brodie MJ, Asbury AJ, Clark C. Inhaled fentanyl as a method of analgesia. Anaesthesia. 1990;45(6):449-51.

77. drugs@FDA database. Food and drug administration. http:// www.accessdata.fda.gov. Accessed 20 Dec 2014.

78. Sou T, Meeusen EN, de Veer M, Morton DAV, Kaminskas LM, McIntosh MP. New developments in dry powder pulmonary vaccine delivery. Trends Biotechnol. 2011;29(4):191-8.

79. EDQM. European pharmacopoeia. 8th ed. Strasbourg: Council of Europe Publishing; 2013.

80. Brandau DT, Jones LS, Wiethoff CM, Rexroad J, Middaugh CR. Thermal stability of vaccines. J Pharm Sci. 2003;92(2):21831.

81. Carstens MG. Opportunities and challenges in vaccine delivery. Euro J Pharm Sci. 2009;36(4-5):605-8.

82. WHO. Progress towards global immunization goal-2012 http:// www.who.int. Accessed 4 Jan 2014

83. Clayborough R, Simpson I. DPI technologies: time for a rethink. IPT. 2010;14:74-9.

84. Grosset KA, Malek N, Morgan F, Grosset DG. Inhaled dry powder apomorphine (VR040) for 'off ' periods in Parkinson's disease: an in-clinic double-blind dose ranging study. Acta Neurol Scand. 2013;128(3):166-71.

85. De Boer AH, Hagedoorn P, Westerman EM, Le Brun PPH, Heijerman HGM, Frijlink H. Design and in vitro performance testing of multiple air classifier technology in a new disposable inhaler concept (Twincer) for high powder doses. Euro J Pharm Sci. 2006;28:171(3)-8.

86. Westermann EM, De Boer AH, Le Brun PPH, Touw DJ, Roldaan AC, Frijlink HW, et al. Dry powder inhalation of colistin in cystic fibrosis patients: a single dose pilot study. J Cyst Fibros. 2007;6(4):284-92.

87. Lexmond AJ, Hagedoorn P, van der Wiel E, Ten Hacken NH, Frijlink HW, de Boer AH. Adenosine dry powder inhalation for bronchial challenge testing, part 1: inhaler and formulation development and in vitro performance testing. Eur J Pharm Biopharm. 2014;86(1):105-14.

88. Saluja V, Amorij JP, Kapteyn JC, de Boer AH, Frijlink HW, Hinrichs WLJ. A comparison between spray drying and spray freeze drying to produce an influenza subunit vaccine powder for inhalation. J Control Release. 2010;144(2):127-33.

89. Needham M, Fradley G, Cocks P. Investigating the efficiency of reverse cyclone technology for DPI drug delivery. In: Dalby RN, Byron PR, Peart J, Suman JD, Farr SJ, Young PM, editors. Proceedings of RDD 2010 (2). River Grove: Davis Healthcare International Publication; 2010. pp. 369-72.

90. Harris DS, Smith SJ, inventors; Cambridge Consultants Ltd., assignee. Dry powder inhalers. US Patent 8261739. 11 Sept 2012.

91. Villax P, McDerment IG, Bunce M, inventors; Hovione International Ltd., assignee. A simple inhaler. US patent 8109267. 7 Feb 2012.

92. Tibbats J, Mendes PJ, Villax P. Understanding the power requirements for efficient dispersion in powder inhalers: comparing CFD predictions and experimental measures. In: Dalby RN, Byron PR, Peart J, Suman JD, Farr SJ, Young PM, editors. Proceedings of RDD 2010 (1). River Grove: Davis Healthcare International Publication; 2010. p. 323-30. 
93. Dinh K, Myers DJ, Glazer M, Shmidt T, Devereaux C, Simis K, et al. In vitro aerosol characterization of Staccato Loxapine. Int J Pharm. 2011;403(1-2):101-8.

94. Teva select brands, Horsham, US. Adasuve prescribing information. http://www.adasuve.com. Accessed 6 Jan 2014

95. Noymer P, Myers DJ, Glazer M, Fishman R, Casella J. The Staccato system: inhaler design characteristics for rapid treatment of CNS disorders. In: Dalby RN, Byron PR, Peart J, Suman JD, Farr SJ, Young PM, editors. Proceedings of RDD 2010 (1). River Grove: Davis Healthcare International Publication; 2010. p. 1321.

96. Myers DJ, Timmons RD, Lu AT, Hale RL, Solas DW, Soni P, et al. Effect of film thickness on thermal aerosol generation. Pharm Res. 2006;24(2):336-42.

97. Noymer PD, Myers DJ, Casella JV, Timmons R. Assessing the temperature of thermally generated inhalation aerosols. J Aerosol Med Pulm Drug Deliv. 2011;24(1):11-5.

98. Dinh KV, Myers DJ, Noymer PD, Casella JV. In vitro aerosol deposition in the oropharyngeal region for Staccato ${ }^{\circledR}$ Loxapine. J Aerosol Med Pulm Drug Deliv. 2010;23(4):253-60.

99. Myers DJ, Spyker DA, Dinh K, Quintana RJ, Cassella JV. Consistency of dosing with a thermal aerosol generation system: and in vivo correlation. Future Med Chem. 2011;3(13):1719-33.
100. Rabinowitz JD, Lloyd PM, Munzar P et al. Ultra-fast absorption of amorphous pure drug aerosols via deep lung inhalation. J Pharm Sci. 2006;95(11):2438-50.

101. Simis K, Lei M, Lu AT, Sharma KCV, Hale RL. Nicotine aerosol generation from thermally reversible zinc halide complexes using the Staccato system. Drug Dev Ind Pharm. 2008;34(9):936-42.

102. Macleod DB, Habib AS, Ikeda K, Spyker DA, Cassella JV, Ho KY, et al. Inhaled fentanyl aerosol in healthy volunteers: pharmacokinetics and pharmacodynamics. Anesth Analg. 2012;115(5):1071-7.

103. Alexza Pharmaceuticals. Staccato product pipeline. http:// alexza.com Accessed 6 Jan 2014.

104. Adler D, Kritzman A, Holtz A, inventors; Aespira Ltd., assignee. Dry powder inhaler. United States patent 13/575908. 21 Feb 2013.

105. Clinicaltrials.gov database, ID:NCT01252758. NIH. http:// www.clinicaltrials.gov. Accessed 6 Jan 2014.

106. Smutney CC et al., inventors; MannKind Corp., assignee. Dry powder inhaler and system for drug delivery. United States patent 8636001. 28 Jan 2014.

107. Team Consulting (Cambridge, UK). Occoris white paper. http:// www.team-consulting.com. Accessed 6 Jan 2014.

108. Jones A, Miller RL, inventors; Manta Corp., assignee. Dose delivery device for inhalation. United States patent 8291901. 23 Oct 2012. 